\title{
Non-invasive technique for diagnosing congenital and acquired ventricular septal defects using directional Doppler ultrasound

\author{
Correlations with phasic flow velocity patterns \\ of the shunt
}

\author{
D. Kalmanson, J. Aigueperse, Colette Veyrat, Claude Cornec, and P. Chiche \\ From the Departments of Cardiology, Fondation Ophtalmologique A. de Rothschild, Hôpital Tenon, and \\ Centre Médico-Chirurgical de la Porte de Choisy, Paris, France
}

In 32 patients with congenital ventricular septal defect and 5 patients with acquired ventricular septal defect from infarction and perforation of the interventricular septum, the jugular venous blood flow velocity was recorded transcutaneously using a directional Doppler velocimeter. In all cases characteristic anomalies of the blood flow pattern were noted. A pathophysiological interpretation of these anomalies is proposed invoking a functional disorder in the behaviour of the tricuspid valve. This explanation is supported by data from 6 patients in whom direct measurements of the blood flow velocity pattern through the septal defects were made at operation.

Specific patterns of the jugular venous flow velocity could be related to the type of ventricular septal defect, classified according to the amount of shunt flow and the degree of pulmonary hypertension.

It is concluded that the transcutaneous Doppler technique provides a new non-invasive method of establishing the diagnosis of ventricular septal defect and of grading the shunt size and degree of pulmonary hypertension.

In most instances, the diagnosis of congenital ventricular septal defect is a result of clinical acumen; however, dye dilution technique or cardiac catheterization is often required to confirm the diagnosis, to rule out an associated defect, and to evaluate the size of the shunt. For many years the need has been felt for a non-invasive method to obtain these results. This particularly applies to acquired ventricular septal defect from perforation of the interventricular septum caused by myocardial infarction, a situation where the differential diagnosis from mitral insufficiency arising from papillary muscle infarction or ruptured chordae tendineae is often raised and cannot always be made by clinical auscultation of the heart or by phonocardiography, and where cardiac catheterization is not always readily feasible or may be hazardous.

Jugular venous pulse recording seemed prom-

Received 2I September 1973. ising. Gelfand (1965) described fine undulations between the $c$ and $v$ waves, ascribed to vibrations of the tricuspid leaflet reflected back to the veins, but in two of his cases the shunt occurred between the left ventricle and the right atrium. All other authors, however, agree that the jugular venous pulse tracing is never altered in patients with ventricular septal defect except when there is associated pulmonary arterial hypertension and even then the alterations of the curve are by no means characteristic of the defect (Wood, 1950; Hartman, 1960; Bory, 1966; Colman, 1966; Gamboa et al., 1965).

It is convenient to recall that in previous publications we reported certain clinical conclusions from recordings of jugular venous flow velocity curves obtained from transcutaneous directional Dopplershifted ultrasound. a) We determined the normal pattern of the curve (Fig. I) and its physiological interpretation (Fig. 2) (Kalmanson, Veyrat, and Chiche, 1968, 1971). b) We described how we could 


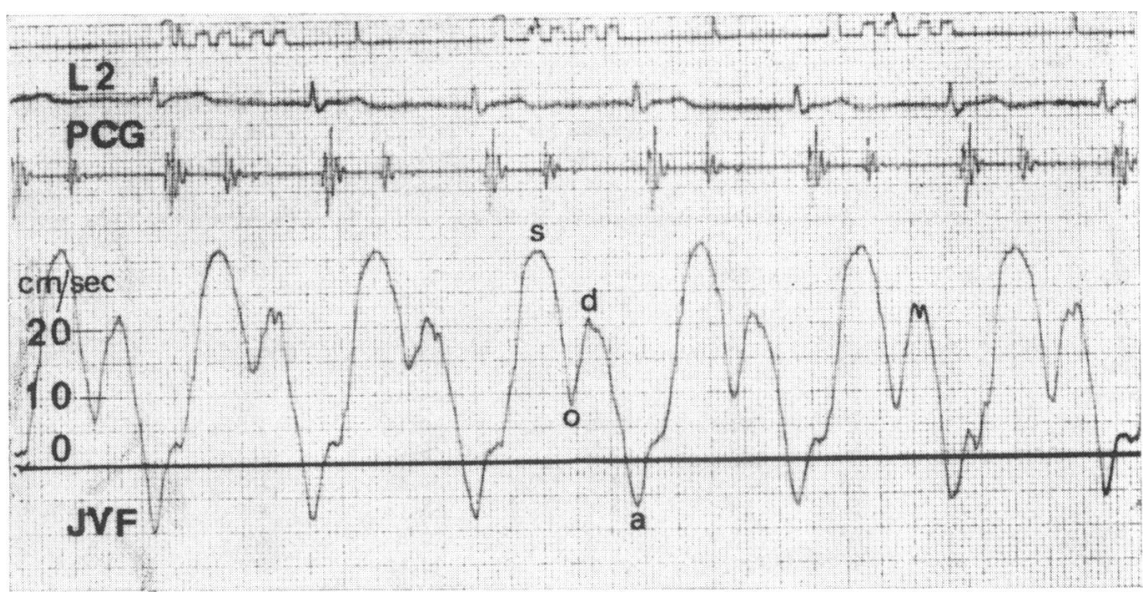

FI I. I fugular venous flow velocity curve in normal subject. Note that the summit of the s wave occurs at the time of the end of the $T$ wave of the electrocardiogram, and is round shaped. Ascending and descending limbs of the $s$ wave are smooth. The o point remains consistently and conspicuously above the zero line. Distance between 2 successive spikes (upper row) equals I sec.
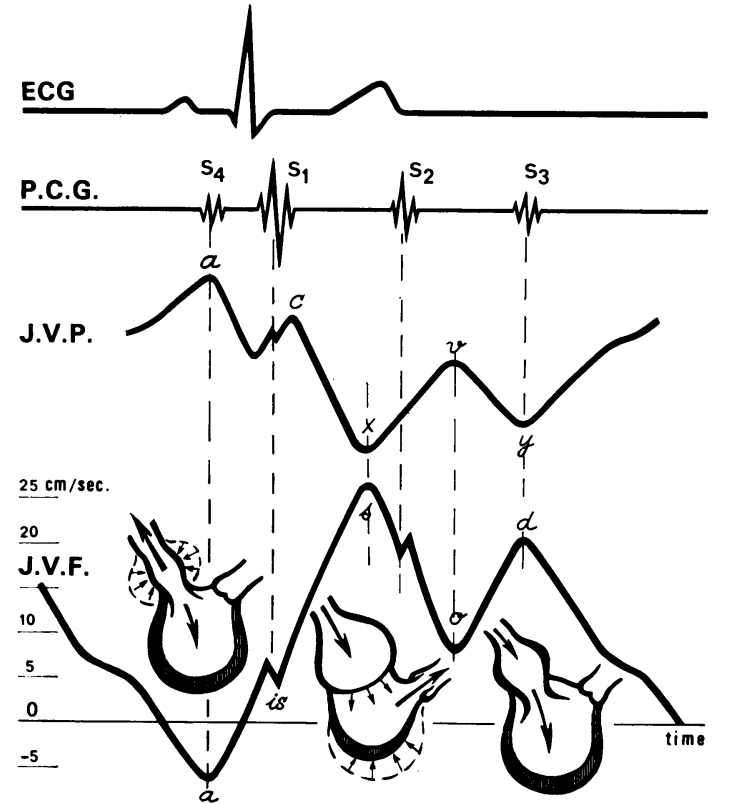

FIG. 2 Normal pattern of jugular venous flow curve, physiological interpretation and time relation. From top to bottom: electrocardiogram, phonocardiogram showing hearts sounds, jugular venous pulse, and jugular venous flow velocity tracings. The negative a wave of the jugular venous flow velocity curve is due to atrial contraction (backflow wave); the positive s wave to both atrial relaxation and downward movement of the tricuspid floor induced by ventricular contraction; the $d$ wave to the rapid filling phase of the right ventricle; is: isometric contraction notch. diagnose atrial septal defect by the characteristic anomalies of the pattern, and how we could correlate these anomalies to the phasic flow velocity pattern of the shunt recorded using a Doppler catheter-tip velocimeter (Kalmanson et al., 1972c). These findings led us to investigate whether the same non-invasive technique (associated with the same pattern recognition method) could be an aid to the diagnosis of congenital ventricular septal defect as well as acquired ventricular septal defect from infarction and perforation of the interventricular septum. They also prompted us to record the phasic flow velocity pattern of the shunt and verify whether it could provide an explanation for the specific anomalies of the curve.

The fact that in all our cases the diagnosis could indeed be assessed by the jugular venous flow velocity anomalies, even in cases where the shunt was small, supports the statement that this type of recording is highly sensitive. However, it is most likely that minute shunts may not be discernible, since their haemodynamic effects on venous return are not significant.

\section{Subjects and method}

\section{A) Thirty-seven patients with ventricular septal defects all in sinus rhythm}

I) Thirty-two patients with congenital septal defect There were 16 women and 16 men, ranging in age from 4 to 38 years. The diagnosis was confirmed in all but 2 cases by cardiac catheterization using the Telco $^{1}$ manometer and/or by angiocardiography. In

1 Telco, 94-Gentilly, France. 
TABLE I Haemodynamic data and classification of patients with ventricular septal defect

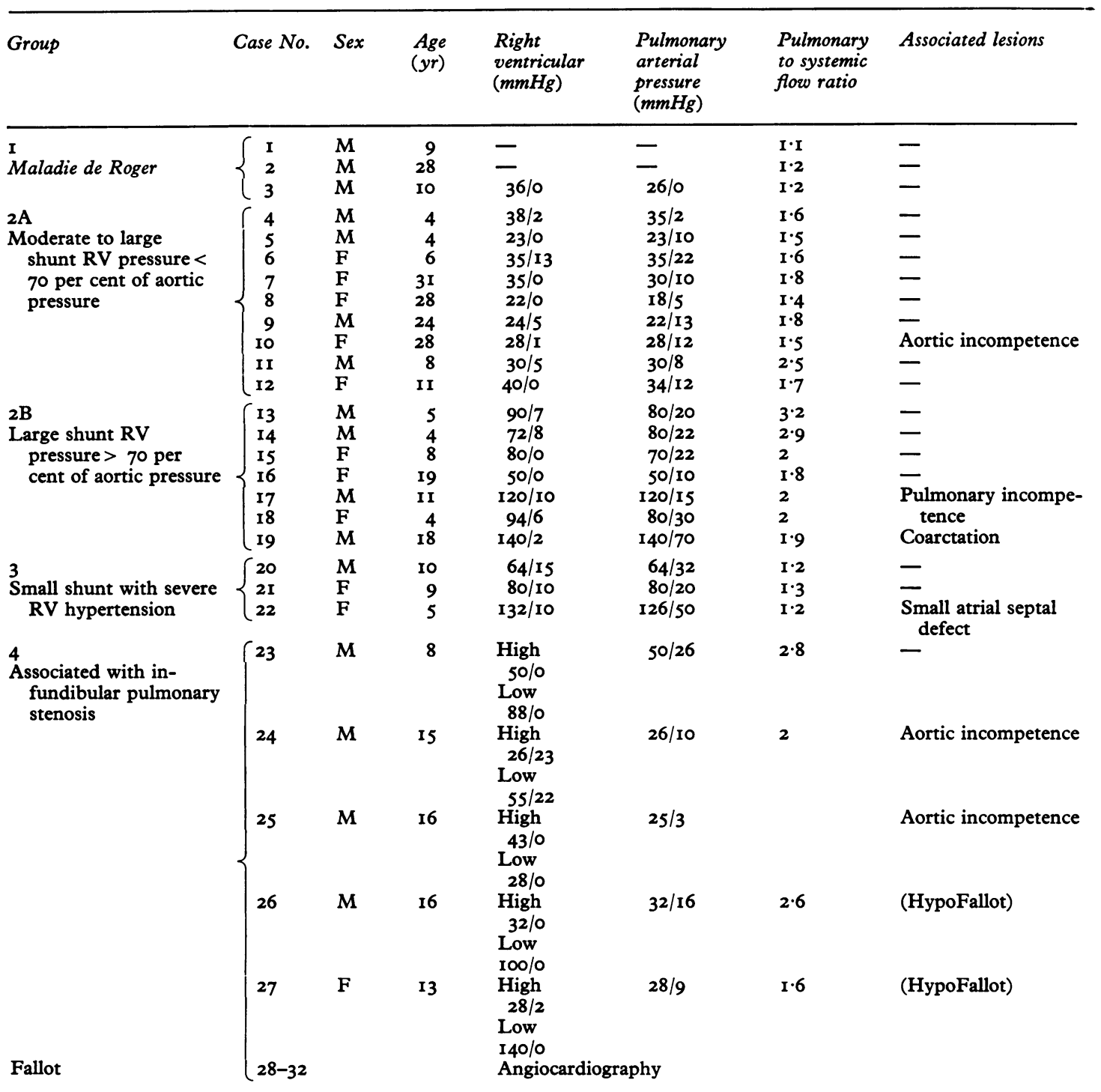

Cases $I$ and 2, the clinical presentation was typical and the diagnosis confirmed by the dye dilution technique using the Waters apparatus. ${ }^{1}$ According to the classification proposed by Nadas (Nadas and Fyler, 1968; Corone et al., 1972), the patients were classified into 5 groups: Group I: Small shunt, normal pressures, Roger's disease (3 patients). Group 2A: Moderate to large shunt, with pulmonary pressures between 30 and 70 per cent of aortic pressure (9 patients). Group $2 B$ : Large shunt with pulmonary arterial pressure above 70 per cent of aortic pressure (7 patients). Group 3: High

1 Waters, Rochester, Minnesota, U.S.A. pulmonary resistances, severe pulmonary hypertension, and small shunt (3 patients). Group 4: An associated infundibular pulmonary stenosis ( 5 patients). In this group we included 2 acyanotic patients (Cases 26 and 27), with high right ventricular pressure ('HypoFallot'). Five additional patients (Cases 28 to 32) with Fallot's tetralogy were also studied. Patients with Eisenmenger's syndrome were not included in this study.

2) Five patients with perforation of interventricular septum occurring after acute myocardial infarction There was $I$ woman and 4 men, ranging in age from 65 to 88 years. In all cases the diagnosis was 
TABLE 2 Haemodynamic and anatomical data of patients with perforation of interventricular septum

\begin{tabular}{|c|c|c|c|c|c|c|}
\hline Case No. & Sex & $\begin{array}{l}\text { Age } \\
(y r)\end{array}$ & $\begin{array}{l}\text { Right } \\
\text { ventricular } \\
\text { pressure } \\
(m m H g)\end{array}$ & $\begin{array}{l}\text { Pulmonary } \\
\text { artery pressure } \\
(m m H g)\end{array}$ & $\begin{array}{l}\text { Pulmonary } \\
\text { to systemic } \\
\text { flow ratio }\end{array}$ & Findings at necropsy \\
\hline $\begin{array}{l}33 \\
34 \\
35\end{array}$ & $\begin{array}{l}M \\
M \\
M\end{array}$ & $\begin{array}{l}67 \\
69 \\
73\end{array}$ & $\begin{array}{l}35 / 0 \\
46 / 13 \\
58 / 12\end{array}$ & $\begin{array}{l}35 / 10 \\
46 / 10 \\
58 / 25\end{array}$ & $\begin{array}{l}- \\
1 \cdot 60 \\
1 \cdot 80\end{array}$ & $\begin{array}{l}\text { Small perforation } 4 \mathrm{~mm} \text { in diameter } \\
\frac{-}{\text { Perforation ro } \times 20 \mathrm{~mm} \text { in anterior and median }} \\
\text { part of septum }\end{array}$ \\
\hline 36 & $\mathbf{F}$ & 85 & - & - & 一 & $\begin{array}{l}\text { Perforation } 15 \times 40 \mathrm{~mm} \text { in the anterior part of } \\
\text { septum }\end{array}$ \\
\hline 37 & $\mathbf{M}$ & 69 & $48 / 7$ & $48 / 23$ & $\mathbf{I} \cdot 30$ & - \\
\hline
\end{tabular}

TABLE 3 The number of subjects in the control groups

Normal subjects

Atrial septal defect

Tricuspid incompetence

Isolated pulmonary stenosis

Isolated pulmonary arterial hypertension

Abnormal communication between aortic root and right ventricle

Isolated mitral incompetence
30

7

IO

I3

2

IO confirmed by cardiac catheterization and/or necropsy. In addition, 3 control groups were studied for comparison (Table 3).

a) Twenty-five normal subjects with normal clinical examination, $x$-rays, and electrocardiogram, or with an innocent systolic murmur at the left sternal border in whom a significant left-to-right shunt was eventually ruled out by cardiac catheterization.

(b) Sixty-two patients: atrial septal defect (30), tricuspid insufficiency (7), isolated pulmonary stenosis (10), pure pulmonary arterial hypertension (13), abnormal communication between aortic root, and right ventricle (2), all in sinus rhythm.

c) Ten patients with confirmed pure mitral incompetence, including 5 cases of acute mitral incompetence from papillary muscle infarction or rupture of the chordae tendineae as a result of myocardial infarction or bacterial endocarditis.

\section{B) Directional transcutaneous ultrasonic Doppler velocimeter}

We used a velocimeter (Sophia ${ }^{1}$ VUS 180 and 135 ), the details and performance of which have been reported elsewhere (Chiche et al., I968; Kalmanson et al., 1972a). This device makes it possible to record and measure externally the mean instantaneous blood flow velocity with reasonable accuracy and to discern its direction. Quite obviously any directional Doppler velocimeter,

\footnotetext{
1 Sophia, 78-Mantes-La-Ville, France.
}

having a satisfactory linearity, and providing a zero flow velocity with reasonable accuracy, might be used as well. The transducer is placed according to a previously described technique behind the medial end of the clavicle with the patient supine (a posture that deserves to be stressed), his head slightly raised on a pillow and turned slightly to the opposite side to the transducer (Kalmanson et al., 1968). The recordings were made with normal quiet respiration and with sustained expiration, and inscribed using a Mingograf 8 I seven-channel or $\mathrm{T}_{34}$ fourchannel direct inkwriting recorder, simultaneously with electrocardiogram lead II and frequency selecting phonocardiogram at the second left intercostal space or at the apex. Chart speed is either 25 or $50 \mathrm{~mm} / \mathrm{sec}$; distance between two successive spikes (upper row) equals I sec. The square notches on the records are irrelevant as far as this text is concerned. Whenever possible, respiration was recorded using a mercuryin-rubber strain gauge stretched over the chest wall.

Volume of the shunt flow was measured either by means of dye dilution curves (indocyanine green) using the Waters apparatus, or calculated from the oxygen saturation of the blood samples obtained during cardiac catheterization. Pulmonary to systemic flow ratio $\frac{\mathrm{PF}}{\mathrm{SF}}$ was calculated from the blood oxygen saturation measurements using the following formula

$$
\frac{P F}{S F}=\frac{o_{2} \text { femoral artery }-o_{2} \text { superior vena cava }}{O_{2} \text { femoral artery }-o_{2} \text { pulmonary artery }}
$$

A summary of the haemodynamic data is presented in Tables $I$ and 2.

\section{C) Preoperative recording of shunt}

In 6 patients with a large shunt with or without pulmonary arterial hypertension, who underwent operation for closure of the defect, a sterile No. 7 French Doppler ultrasonic velocimeter catheter tip (Kalmanson et al., 1972a) was introduced at operation into the right ventricle through a small ventriculotomy and placed at the site of the septal defect. The velocity catheter measures the instantaneous blood flow velocity approximately $5 \mathrm{~mm}$ ahead of its tip, and discerns forward and reverse (but not lateral) flow. The technique has been described elsewhere (Kalmanson et al., 1972a). The flow velocity 
patterns of the shunt were recorded during artificial respiration in the anaesthetized patients and inscribed on a four-channel Mingograf 34 direct inkwriting recorder, with simultaneous electrocardiogram and, whenever possible, the epicardial phonocardiogram.

\section{Results}

\section{I) Jugular venous flow velocity traces}

The recorded curves represent the average instantaneous velocity of the jugular venous flow calibrated in $\mathrm{cm} / \mathrm{sec}$, with a sufficiently satisfactory approximation for clinical purposes (Kalmanson et al., I968).

Normal subjects The normal curve (Fig. I) displays a positive systolic wave (s), triangular in shape, with two smooth limbs and a peak that occurs at the end of the electrical $T$ wave immediately before the pulmonary component of the second heart sound; a positive diastolic wave (d); and a partly negative end-diastolic wave (a).

Patients with congenital ventricular septal defect The most obvious changes were found in Group 2A which will therefore be described before Group I, in whom the modifications were more subtle.
Group $2 A$ This group comprised patients with moderate to large shunt and normal or moderately raised pulmonary arterial pressures. Fig. 3 and the diagraps in Fig. 5 display the main pattern found in these cases. The basic anomaly starts in early or mid-systole. In typical cases the curve, after a normal ascent during early systole, shows a premature peak, occurring before the peak or even the onset of the $T$ wave of the electrocardiogram. The descent of the $s$ wave therefore starts earlier and has a smaller gradient than normal. It also shows a series of saw-tooth indentations, more or less irregular, for the first half of the descent or even further. The subsequent diastolic $d$ and a waves usually remain normal.

In particular the $O$ point of the junction between the $s$ and $d$ waves usually remains above the zero line (except when shunting occurs partly between the tricuspid leaflets into the atrium, Fig. 4). This typical pattern is subject to small variations (Fig. 4 and 5). The s wave may present a precipitous fall during midsystole, followed by an end-systolic, clearly indented plateau; or it can be cut off, and its peak replaced by a flat or more or less rounded, irregularly indented plateau. Quite often the various patterns show up successively in the same patient.

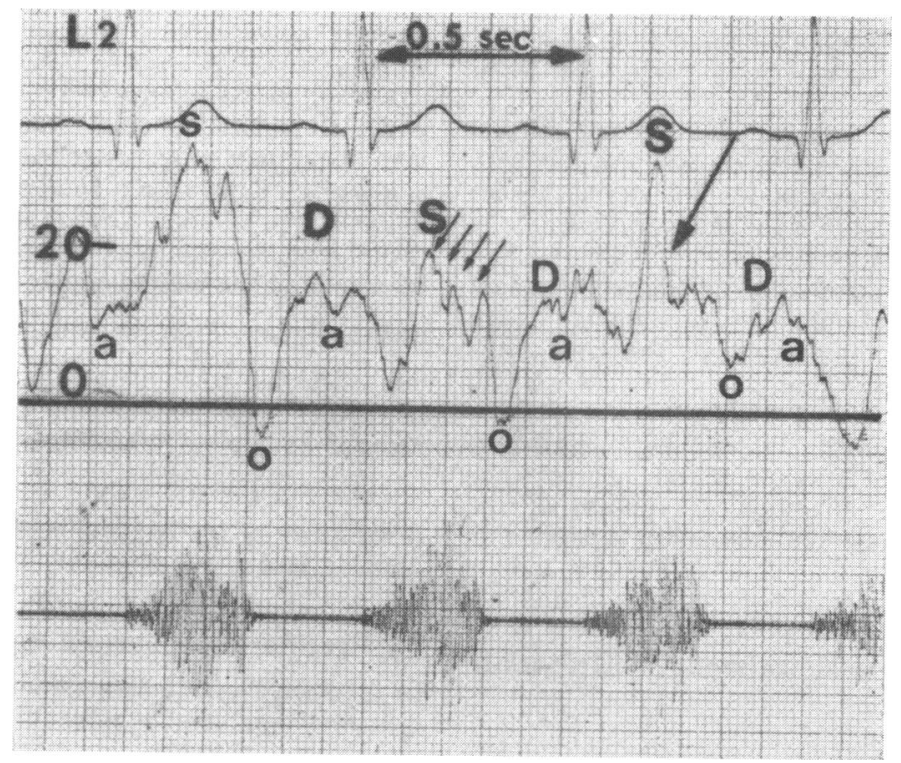

FIG. 3 fugular venous flow velocity curve in ventricular septal defect. Various patterns in group $2 A$. Case 4 in Table I. From top to bottom: electrocardiogram lead II, phonocardiogram recorded at the 4th left intercostal space, and flow velocity curve calibrated in $\mathrm{cm} / \mathrm{sec}$. After a normal early systolic ascent of the $s$ wave, the peak is early, occurring at or even before midsystole, the descending limb has a slower descent than normal and shows conspicuous notches all along the descent or falls precipitously and then discloses the characteristic indentations (last complex to the right). 


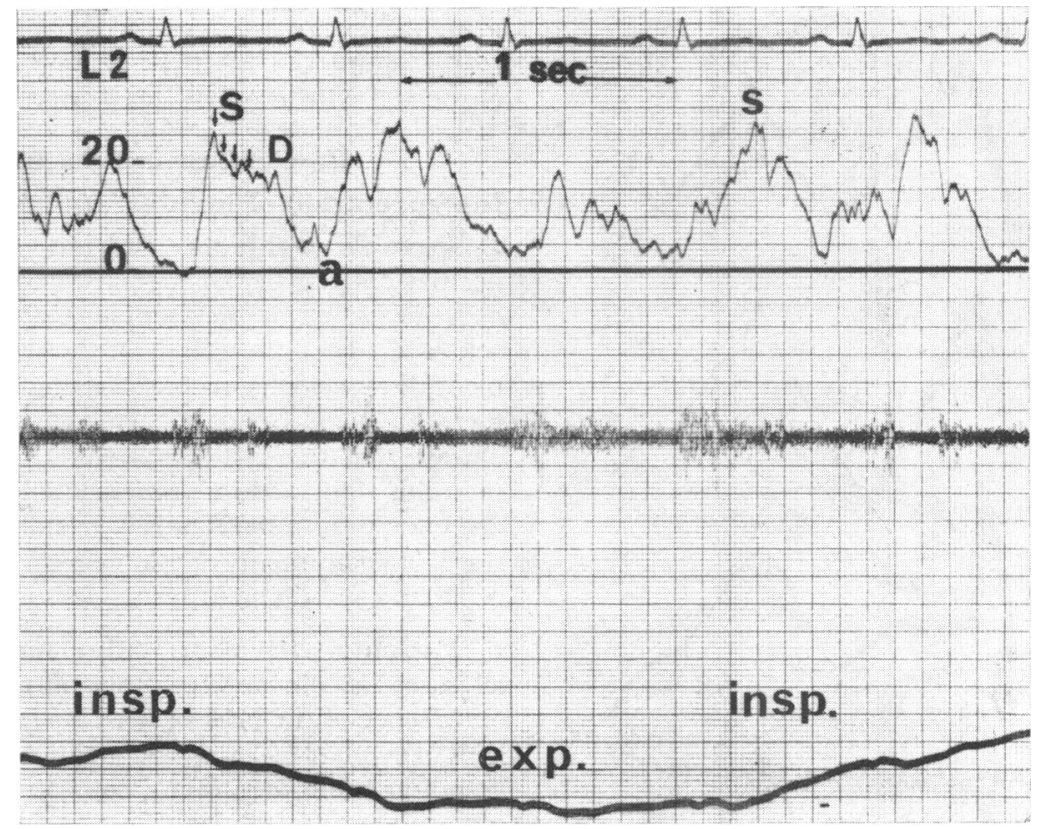

FIG. 4 fugular venous flow velocity in ventriclar septal defect. Group $2 A$ (large shunt, normal pulmonary arterial pressure). Case 9. Variation of the systolic pattern with respiration. Note the characteristic identations on the descending limb of the swave starting at onset of expiration and the occurrence of indentations on the ascending limb during inspiration. Expiration clearly enhances the magnitude and early occurrence of indentations, which are the clue to diagnosis.

The anomalies are always enhanced by expiration: the summit of the $s$ wave occurs earlier, the amplitude of the wave is still smaller, the indentations are more conspicuous. During inspiration the descending limb of the $s$ wave may appear normal in shape and timing, but the ascending limb is then slanted and in turn shows irregular indentations (Fig. 4).

Group $2 B$ This group comprised patients with a large shunt with high pulmonary arterial pressure (Fig. 6, 7, and 10). The anomalies of the curve are similar, but in addition the a wave is usually conspicuously deeper, the overall amplitude of the $s$ wave decreased, and the indentations occur earlier. Group I: maladie de Roger (see Fig. 8) During inspiration the anomalies of the $s$ wave are usually imperceptible, but the peak of the s wave may be a little premature and the indentations of the descending limb, if present, are very small. However, the typical pattern is elicited during expiration.

Group 3 In this group there is a small shunt and severe pulmonary arterial hypertension (Fig. 9 and 10). If the shunt is still significant, the pattern is similar to that of Group $2 \mathrm{~B}$, but the s wave is almost lost. The a wave is very deep. If the shunt is not significant, the typical pattern is replaced by a high s wave which is conspicuously delayed.

Group 4 and Fallot's tetralogy (Fig. I1, 12, and I3). In both cases, during expiration the typical pattern is elicited; but during inspiration, the peak of the $s$ wave is delayed.

Patients with perforation of interventricular septum The same patterns, as noted in congenital defects, were found in all 5 cases with the same variations induced by respiration (Fig. I4 and 15).

Patients with right heart diseases and without ventricular septal defects Detailed reports have been published on the anomalies of the jugular venous flow patterns which we have found in patients with right heart disease (Kalmanson et al., 1972b). In none of the control group of patients with right heart disease did we find jugular venous flow curves similar throughout the respiratory cycle to the curves recorded from the patients with ventricular septal defects, described above, though simi- 


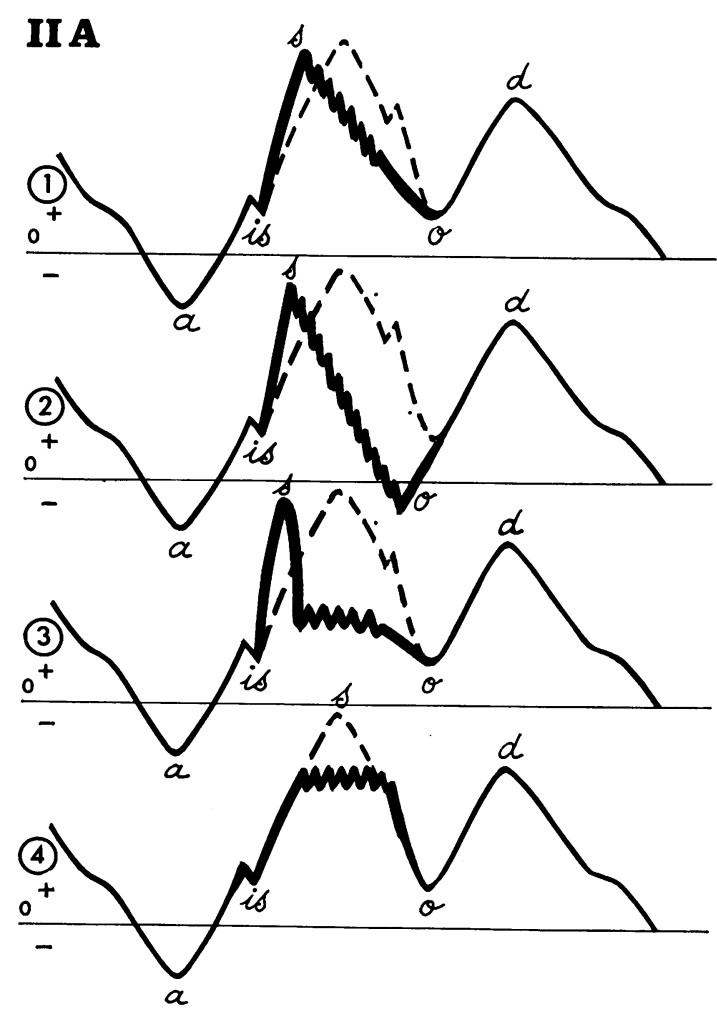

FI G. 5 Stylized diagrams of the jugular venous flow anomalies in group $2 A$. The basic anomaly is an amputation of the systolic $s$ wave, starting either near its summit ( $I$ and 2), or on its descending limb (3), or on its ascending limb (4). The anomalous part of the $s$ wave shows conspicuous indentations. The $o$ point usually remains above the zero line, except when the shunt partly occurs between the tricuspid leaflets into the right atrium (2). (a: atrial contraction wave; is: isometric contraction notch; s: systolic inflow wave; $d$ : diastolic inflow wave; $0:$ junction point of $s$ and $d$ waves.)

larities could be found in some cases if the changes with respiration were not taken into account.

2) Intracardiac flow velocity patterns of shunt Though a more complete and detailed publication is in preparation we present in Fig. 16 to 18 the main patterns encountered. As a convention, positive deflection represents a flow velocity of a left-toright shunt and negative deflection that of a right-toleft one. Fig. I6 shows a large positive wave, starting in early systole, presenting a maximum in mid or late systole, followed by a second maximum in early diastole. Fig. 18 discloses also a large, positive, mainly systolic wave, overlapping early diastole, and a smaller end-diastolic positive wave. In very early systole a minute negative wave may appear, synchronized with the first heart sound (Fig. 17).

\section{Comments and discussion}

\section{Interpretation of jugular venous flow curves}

I Normals subjects Previous studies of the normal pattern of the jugular venous flow velocity curve recorded by the Doppler technique (Kalmanson et al., 197r) as well as of the normal vena caval blood flow velocity recorded using the bristle flowmeter in dogs (Brecher, I956) have led to the conclusion that the systolic acceleration of blood flow into the right atrium (represented by the $s$ wave) originated from both atrial relaxation and downward displacement of the closed tricuspid floor occurring simultaneously.

2) Patients with ventricular septal defect In all cases, a constantly or intermittently premature occurrence of the peak of the s wave, followed by an irregular plateau or by a slanted, saw-tooth descending limb was found, indicating that the systolic inflow into the right atrium was slowed down prematurely and that this slowing down proceeded during late systole until the beginning of diastole.

These alterations of the jugular venous flow curve are subject to respiratory variations: they are enhanced, and sometimes elicited only by light or deep expiration. They may disappear during inspiration. This is particularly the case in patients with a small perforation of the interventricular septum caused by myocardial infarction. It seems reasonable to assume that these effects of slowing down of blood flow are related to, and probably provoked by, a haemodynamic disturbance occurring in the right ventricle produced by the shunt from the left ventricle and transmitted through the closed tricuspid floor into the right atrium.

The finding that in 37 cases of confirmed congenital or acquired ventricular septal defect, the jugular venous flow curve consistently showed these characteristic anomalies proves that this technique provides a non-invasive diagnostic method for ventricular septal defect. Furthermore, our findings suggest the following pathophysiological explanation.

A pathophysiological explanation: tricuspid dysfunction concept The normal systolic jugular venous flow pattern is dependent on two factors. In patients with isolated ventricular septal defect and normal atrial relaxation, the only other remaining factor playing a role in determining the systolic pattern is necessarily the downward displacement of the closed tricuspid floor. Consequently, if this pattern turns out to be consistently altered, its 


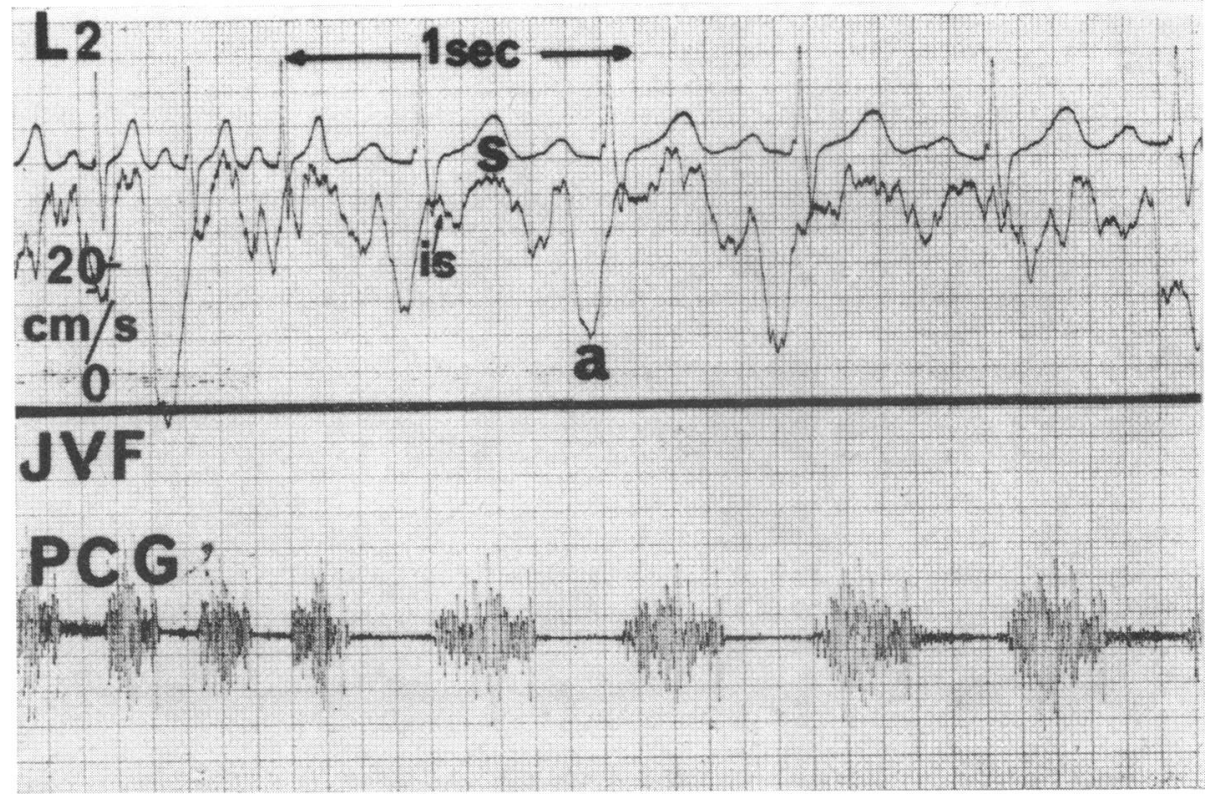

FIG. 6 fugular venous flow velocity curve in ventricular septal defect with large shunt and severe pulmonary arterial hypertension. Case I8 (a constant flow is superimposed on the pulsatile flow). The $s$ wave is squashed, the indentations start very early in systole. Note the very deep a wave.

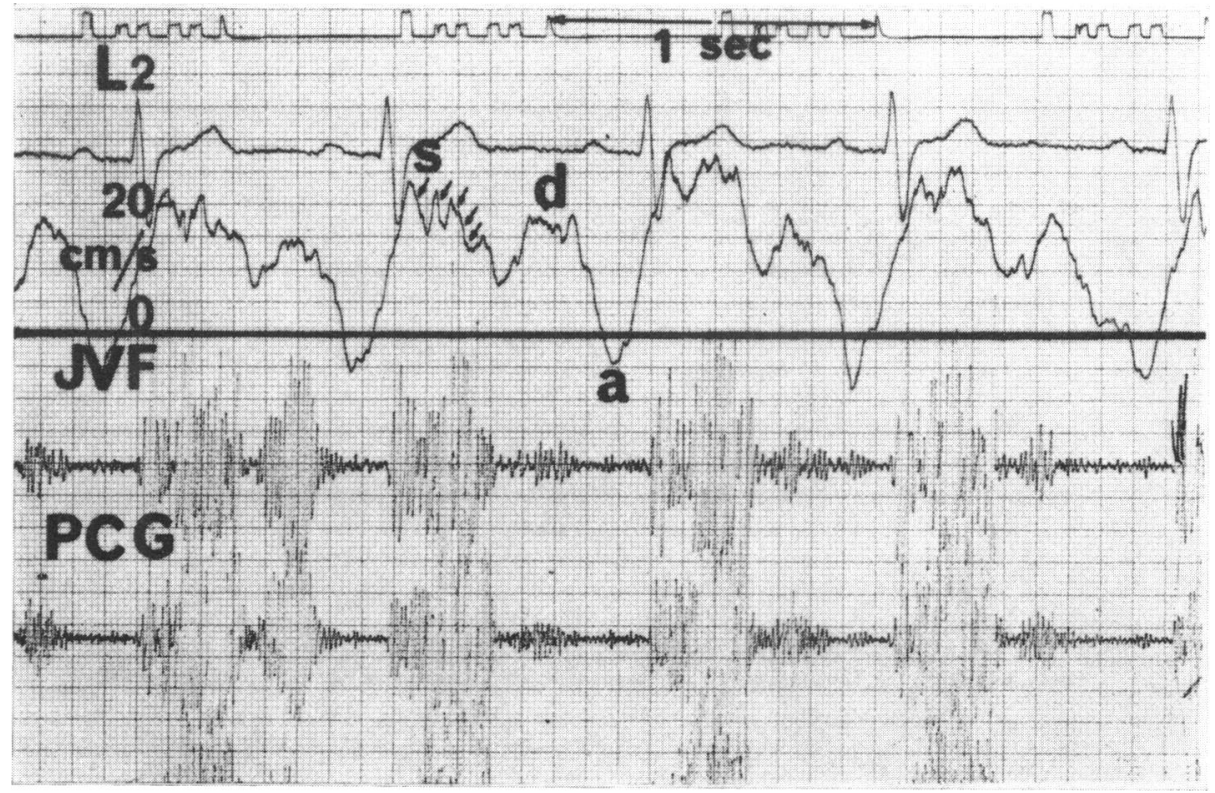

FIG. 7 fugular venous flow velocity curve in ventricular septal defect with large shunt and equalized pulmonary and aortic pressures. Case 17. The pattern is very similar to that of Fig. 6. In addition, the existence of a severe pulmonary insufficiency (with a loud diastolic murmur) induces a decreased and notched $d$ wave (due to diastolic tricuspid dysfunction, Kalmanson et al., $1972 d$ ). 


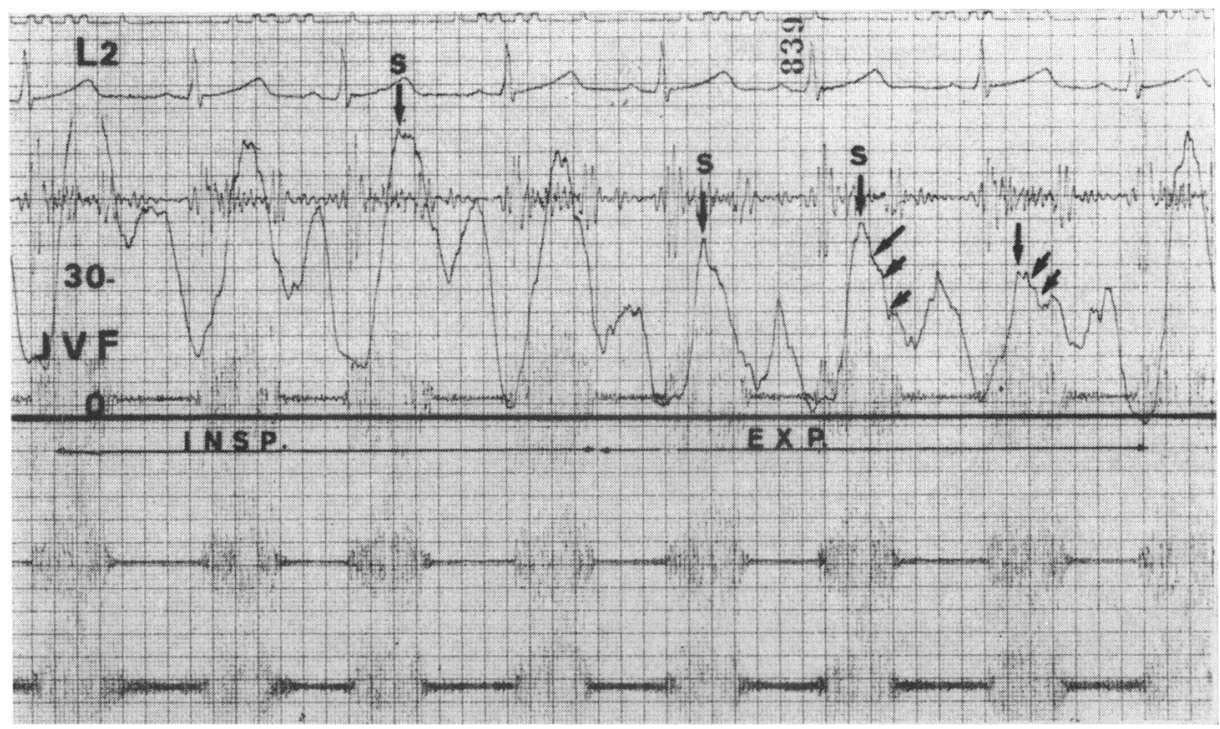

FIG. 8 fugular venous flow velocity curve in Roger's disease. Case 3. The curve is almost normal during inspiration. The typical pattern only shows up during expiration.

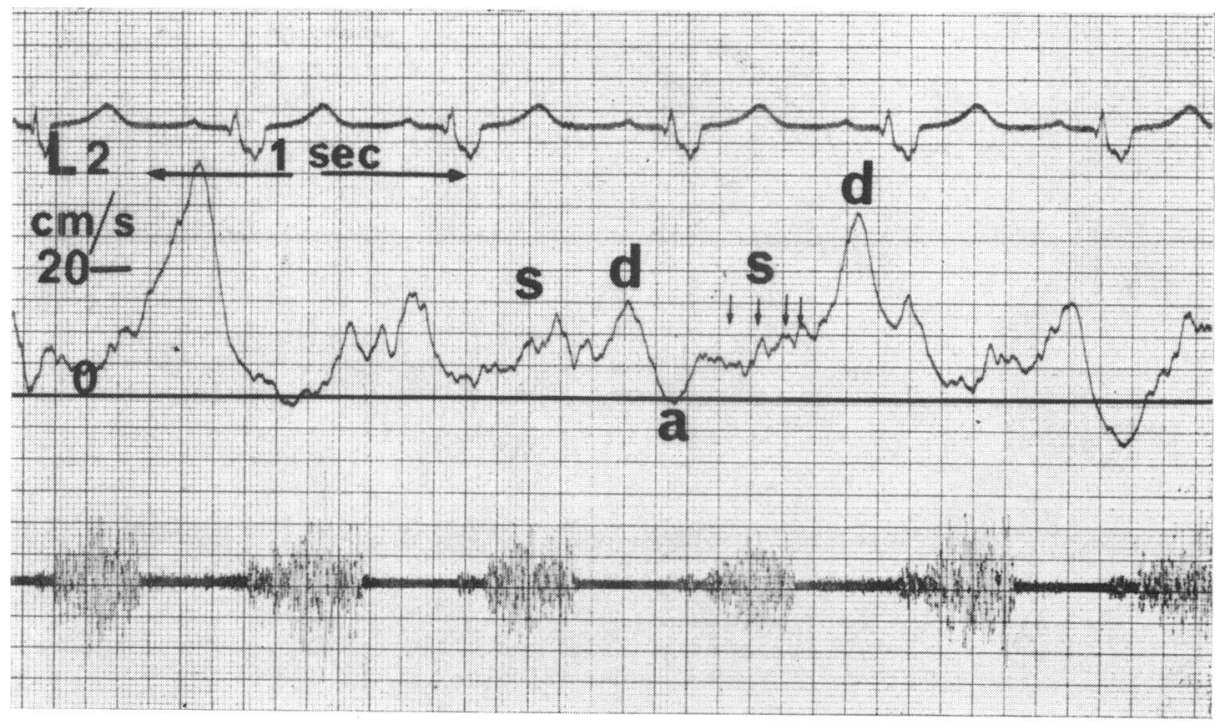

FIG. 9 Fugular venous flow velocity curve in ventricular septal defect with small shunt due to severe pulmonary hypertension. Case 2I. The $s$ wave is of low amplitude and shows coarse indentations. During inspiration the $d$ wave is clearly enhanced, but the swave remains unchanged. 


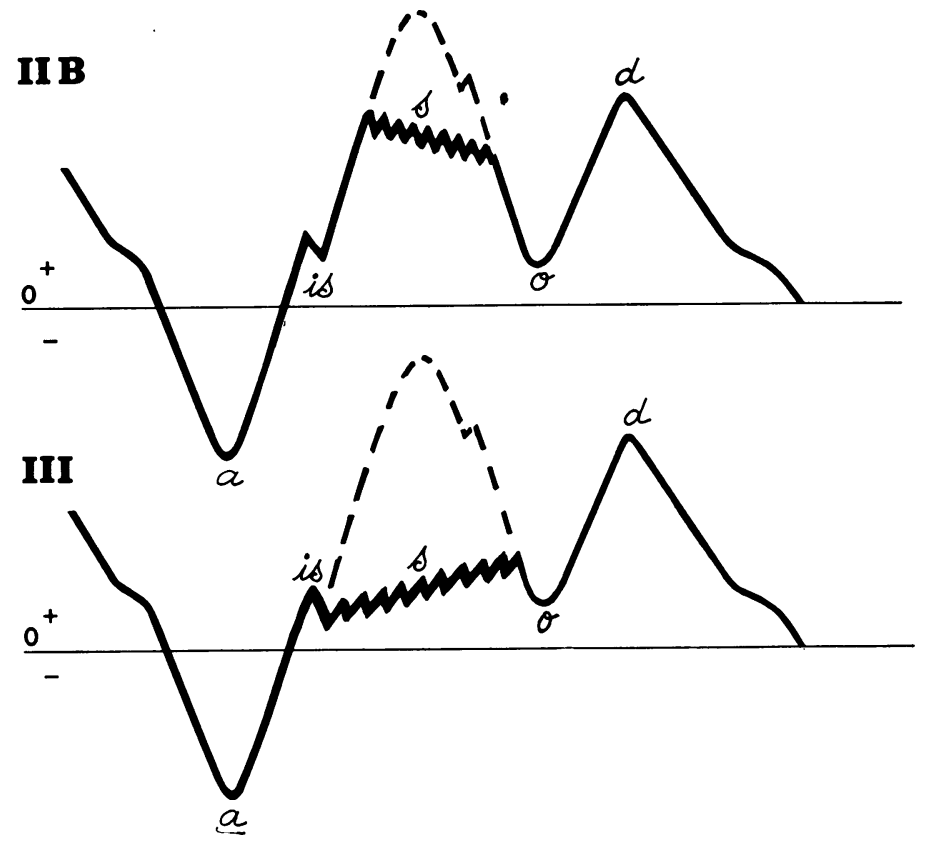

FIG. Io Stylized diagrams of the jugular venous flow anomalies in groups $2 B$ and 3. In group $2 B$, the amputation of the $s$ wave is similar to those of group $2 A$, but the depth of the negative a trough is conspicuously larger. In group 3 , the amplitude of the $s$ wave is and remains very small during the respiratory cycle.

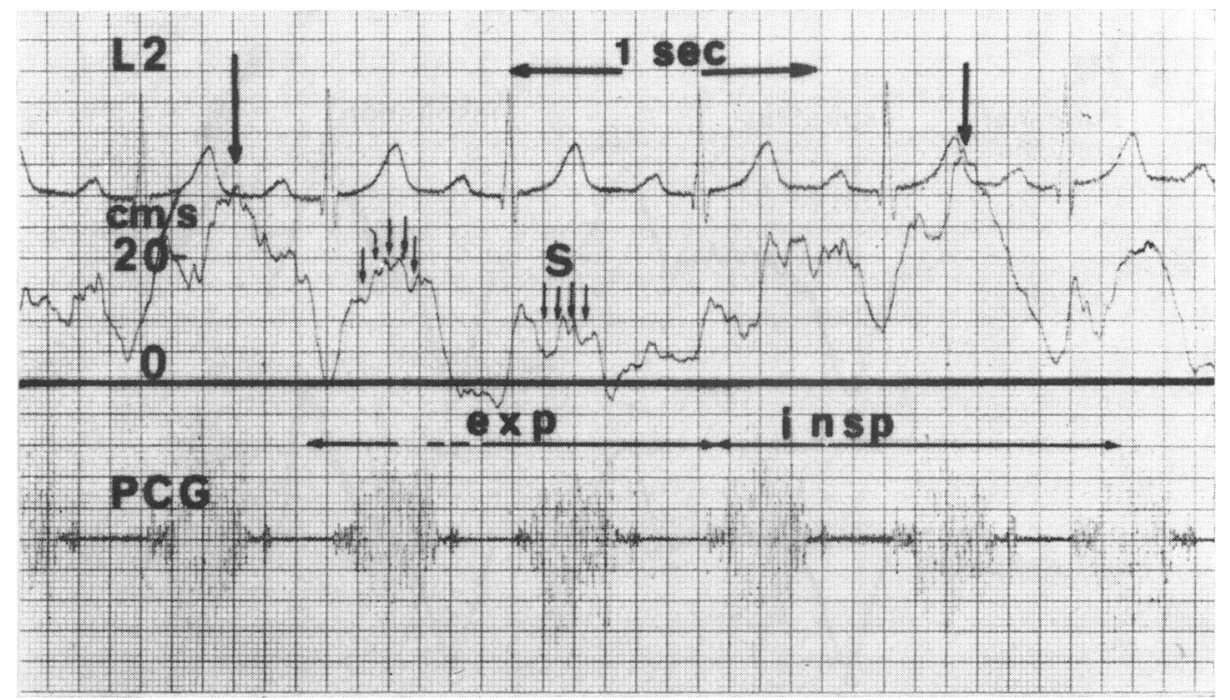

FIG. II fugular flow velocity curve in ventricular septal defect with associated pulmonary stenosis. Case 23. The pattern is typical of ventricular septal defect with hypertension and a large shunt during expiration, but during inspiration notches appear on the ascending limb of the $s$ wave, the summit of which becomes delayed (which discloses the pulmonary stenosis). 


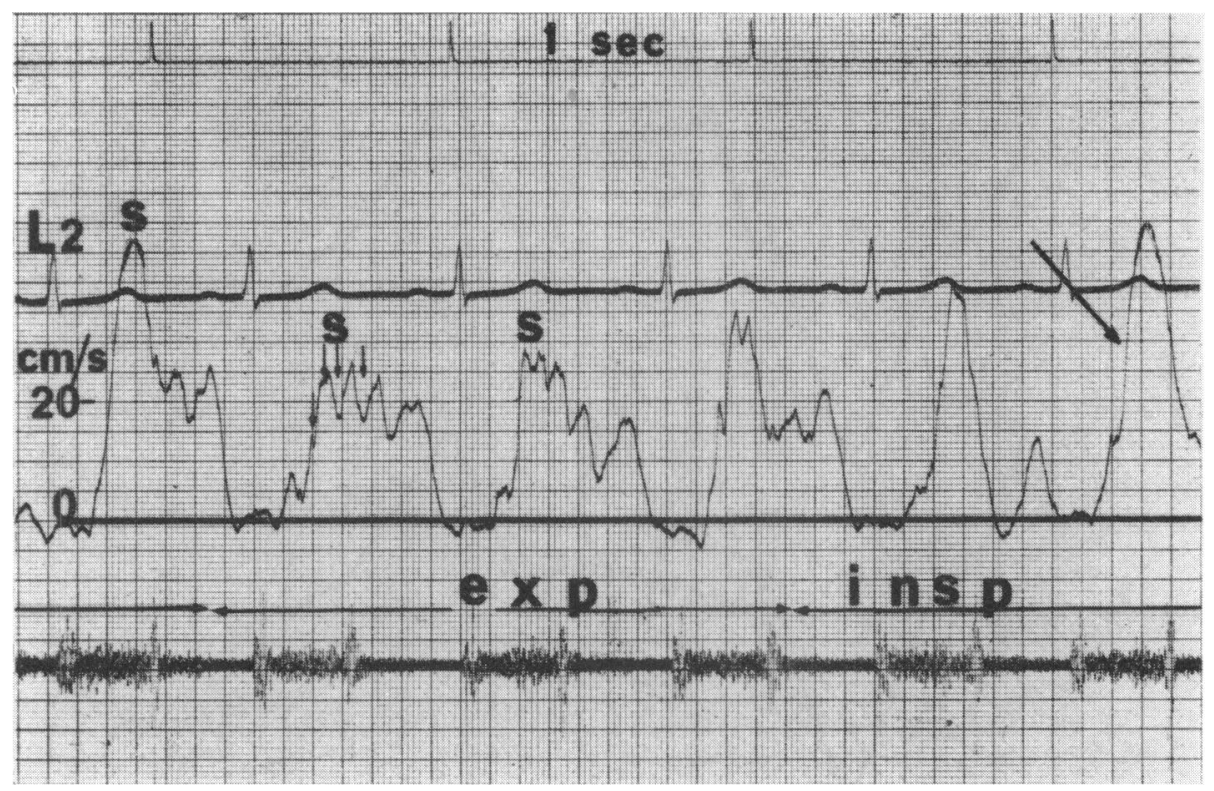

FIG. 12 fugular venous flow velocity curve in Fallot's tetralogy. Case 28. The patterns are similar to that of Fig. 9, but during inspiration the ascending limb of the swave here remains smooth due to the infundibular stenosis. Note the difference of timing of the summit of the swave between expiration and inspiration.

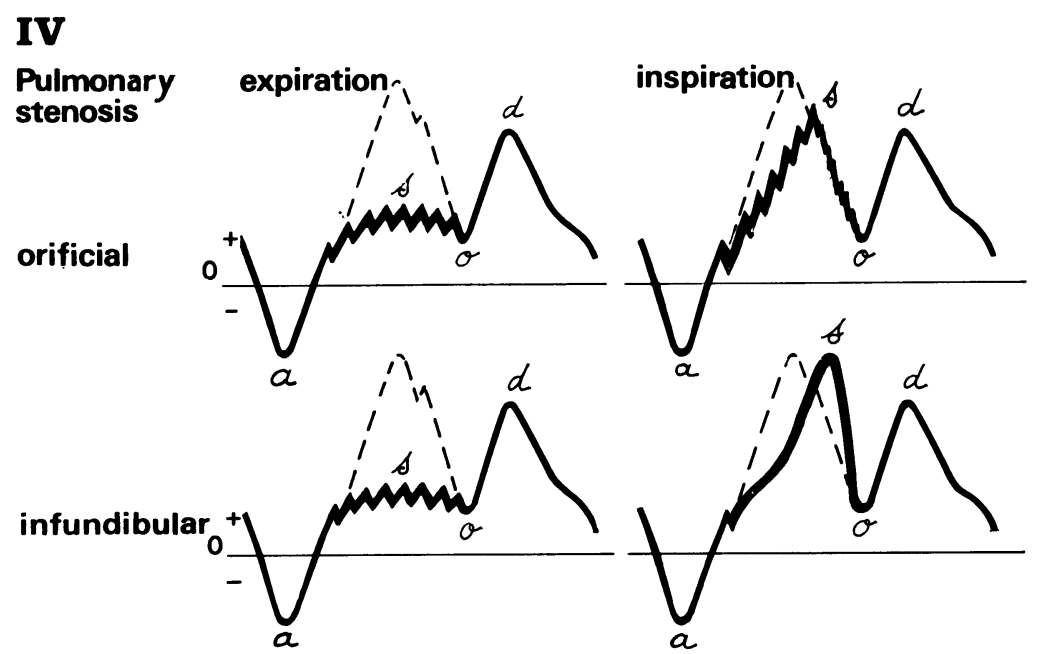

FIG. I3 Stylized diagrams of the jugular venous flow anomalies in group 4 and Fallot's tetralogy. During expiration, in both cases the swave is cut off prematurely and shows the characteristic indentations; but during inspiration, the amplitude of the $s$ wave is enhanced, its summit becomes delayed, and the ascending limb of the $s$ wave shows or does not show indentations depending on whether the stenosis is orificial or infundibular. 


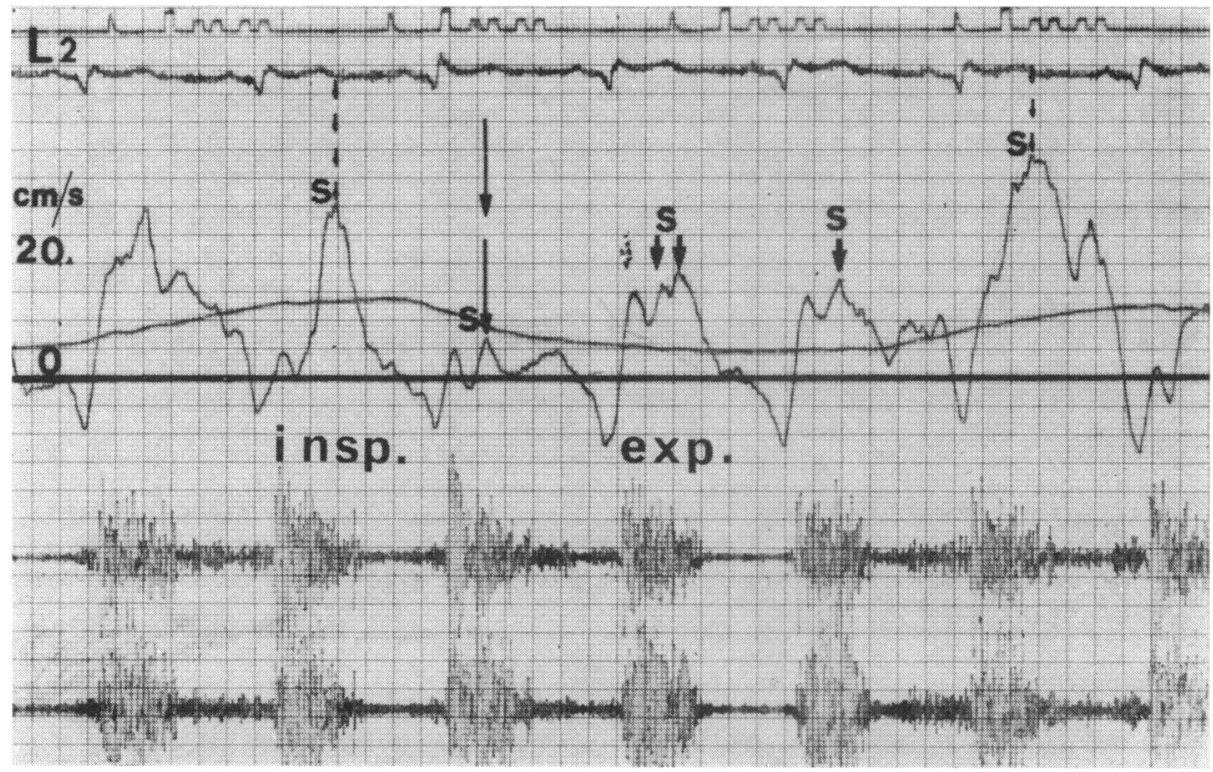

FIG. I4 Fugular venous flow velocity curve in patients with perforation of interventricular septum due to myocardial infarction. Case 33. During expiration, the typical indentations of the $s$ wave are disclosed, but they almost disappear during inspiration.

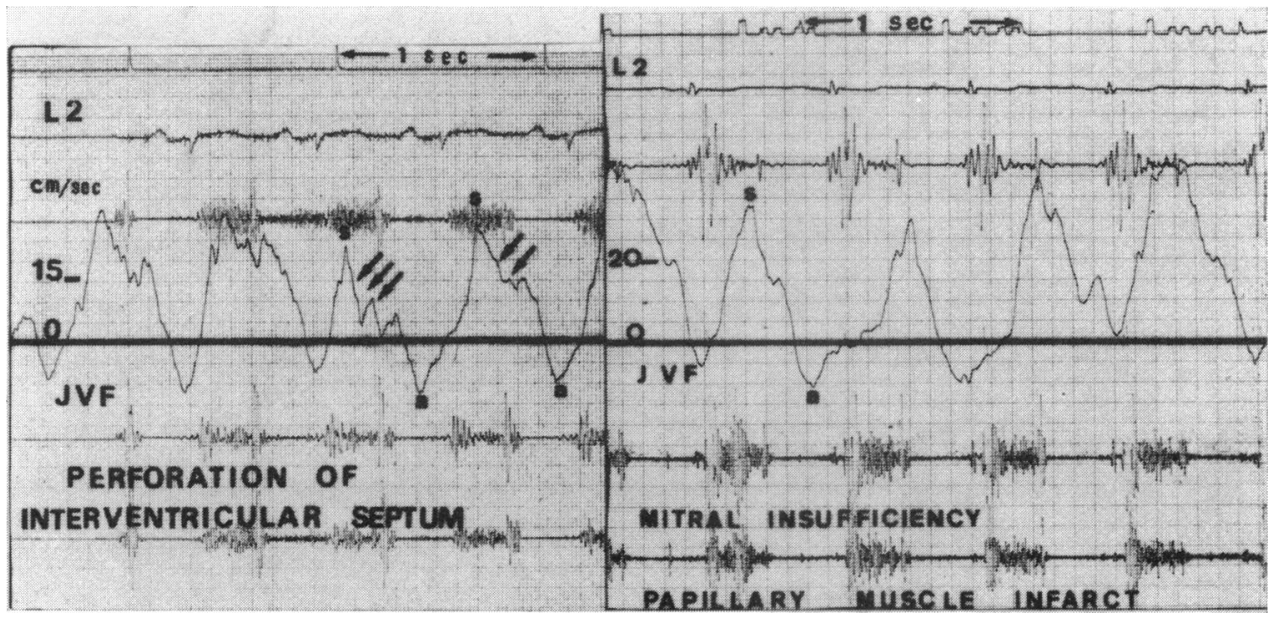

FIG. I5 Fugular venous flow velocity curve as a clue to differential diagnosis of a pansystolic murmur occurring during myocardial infarction. Case 35. Left: the pattern is typical of that of congenital ventricular septal defect, and suggests an acquired perforation of the septum. Right: no such indentations can be disclosed, ruling out the perforation and favouring the diagnosis of mitral incompetence due to papillary muscle infarction. (Both cases were confirmed by necropsy.) 


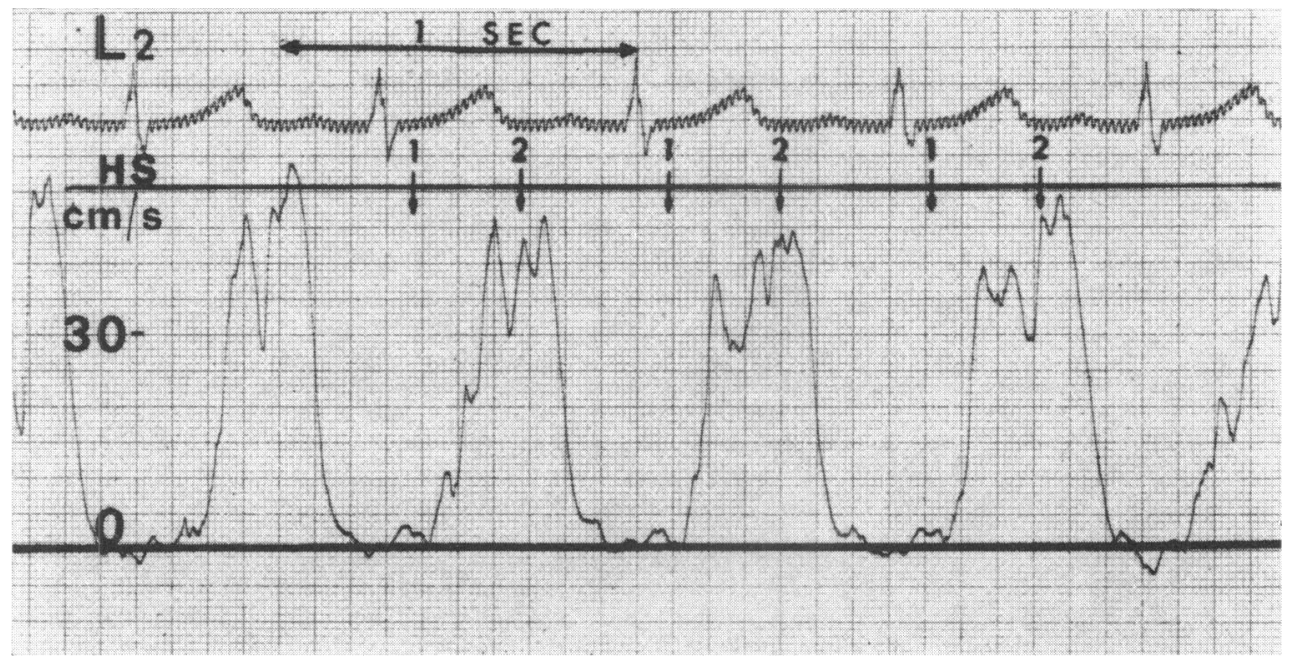

FIG. I6 Shunt flow velocity curve of a ventricular septal defect, recorded preoperatively (patient not listed with large defect and raised pulmonary pressure, group $2 A$ ). From top to bottom: electrocardiogram, external phonocardiogram reproduced from a trace recorded immediately before thoracotomy, shunt flow velocity. Positive velocities refer to left-to-right shunting. The curve starts in early systole, immediately after the first heart sound, climbs rapidly, and is maximum at end-systole, overlaps early diastole where it shows a second maximum, then falls precipitously to the baseline.

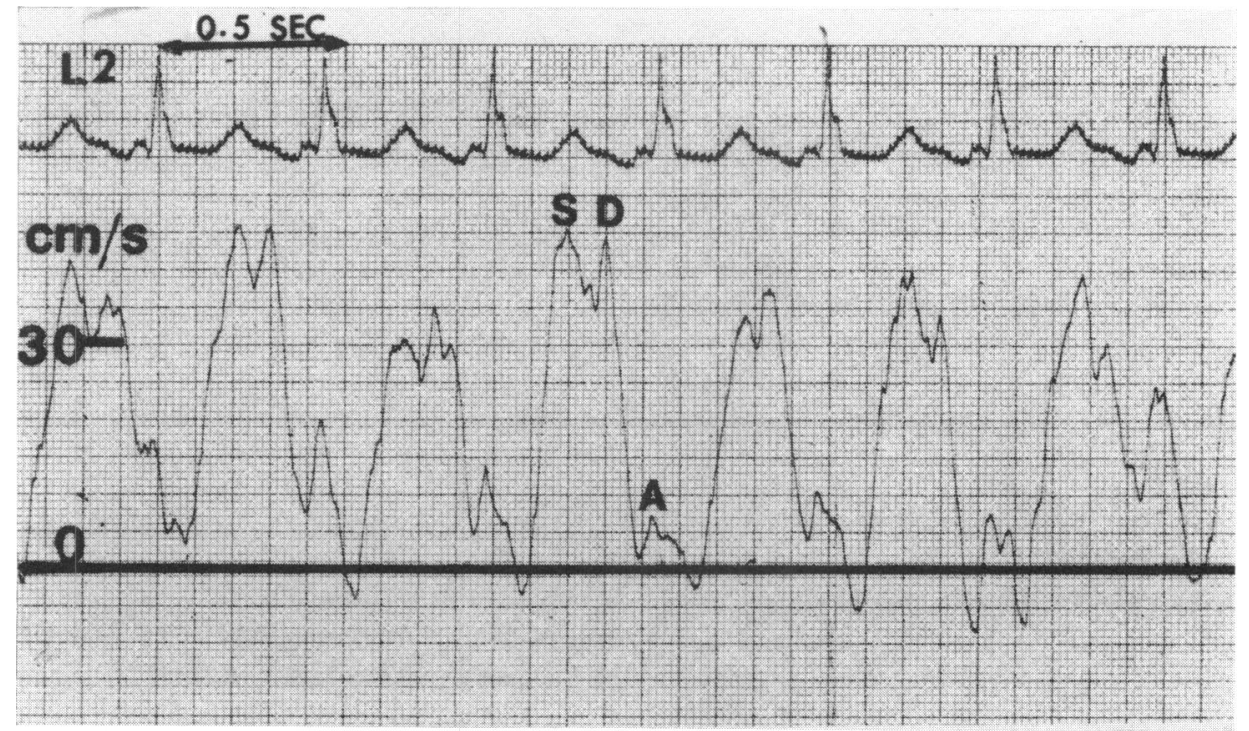

FIG. I7 Shunt flow velocity of a ventricular septal defect with large shunt and pulmonary hypertension recorded preoperatively. Case 15. The pattern is similar to that of Fig. 16: note that the flow continues throughout diastole with a maximum in early diastole, and a lesser one during atrial contraction (the rhythm is nodal). Note the minute negative wave (right-to-left shunt) in early systole. 


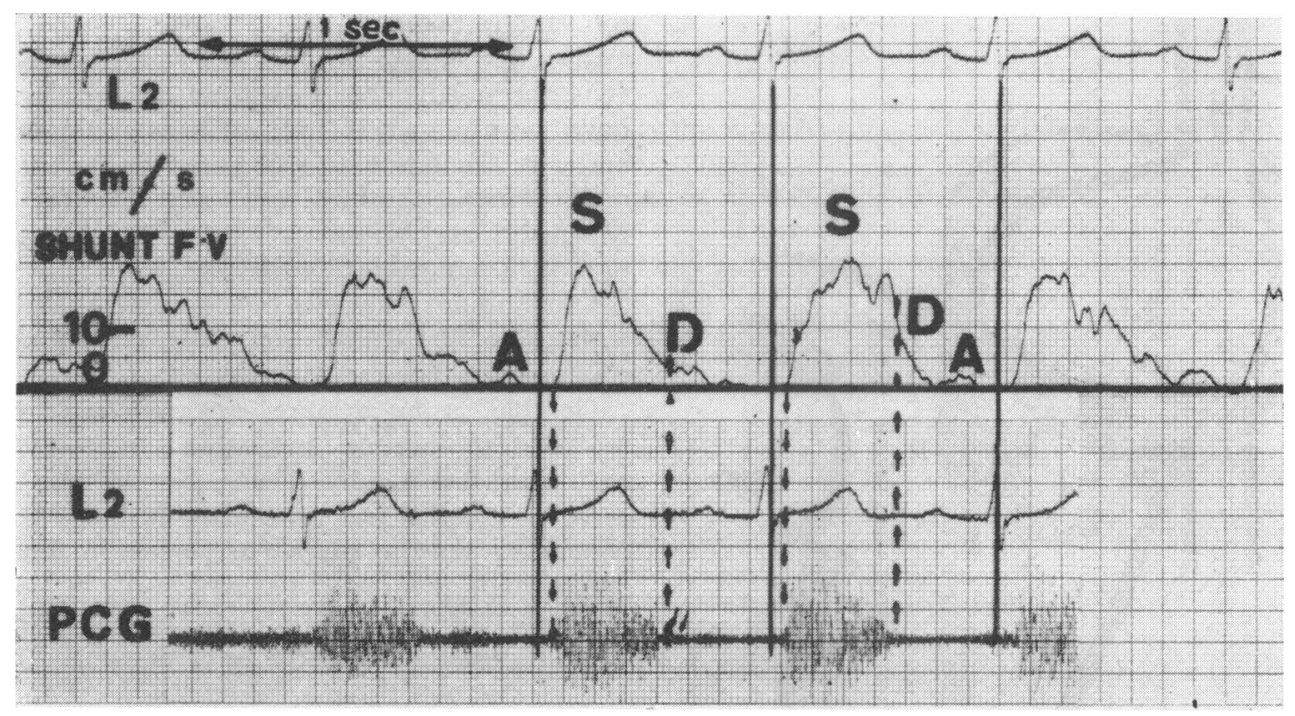

FIG. I8 Shunt flow velocity of an interventricular septal defect with a large shunt and normal pulmonary pressures. Case 8. From top to bottom: electrocardiogram, shunt flow velocity, phonocardiogram at the 4th left intercostal space. The latter was not recorded simultaneously, but before thoracotomy. Both velocity trace and phonocardiogram are mounted together to show time relation. Note that the shunt flow continues slightly into early diastole and is of longer duration than the murmur of ventricular septal defect.

modifications, therefore, must be produced by an anomaly of valve displacement.

Indeed, in a previous study of 75 patients with isolated right ventricular diseases in whom an organic, anatomical, alteration of the tricuspid valve and of the right atrium was ruled out, anomalous patterns of the systolic wave of the jugular venous flow curve were consistently elicited (Kalmanson et al., 1972d). These findings suggested that only severe downward displacement of an otherwise anatomically sound tricuspid valve could explain the occurrence of such alterations of systolic venous return pattern. For this functionally anomalous displacement of the tricuspid floor, we suggested the term 'tricuspid dysfunction' (Fig. 19).

In the particular case of ventricular septal defect, it might be suggested that the shunting flow into the right ventricle, which occurs mainly during systole, opposes the normal descent of the tricuspid floor from early or mid-systole to end-systole. This slowing down of the normal descent in turn would influence the filling of the right atrium, and subsequently the systolic caval flow towards the heart, which becomes slowed down during the same period. Furthermore, the indentations of the descending limb of the $s$ wave might well be explained by the vibrations of the tricuspid leaflet provoked by the shunting jet and transmitted to the veins, as suggested by Gelfand for the jugular venous pulse tracing. In addition, in some cases, the shunt occurred through the interspace between the anterior and septal leaflets of the tricuspid valve, a finding that was proved at operation and provides an alternative - but only occasional - explanation of the jugular venous flow anomalies.

Respiratory variations of jugular venous flow anomalies Expiration simultaneously decreases systemic venous return (Brecher, 1956) (and right ventricular filling) and increases pulmonary venous return (and left ventricular filling). It therefore decreases the left-to-right shunt. Inspiration produces the reverse effects. Furthermore, inspiration also increases pulmonary arterial flow. These physiological effects explain i) why the ventricular septal defect pattern of the jugular venous flow curve is enhanced during expiration, and conversely why it may be normal during inspiration; ii) why inspiration, which increases pulmonary arterial flow, may create a functional pulmonary stenosis and make the characteristic indentations of the latter appear on 


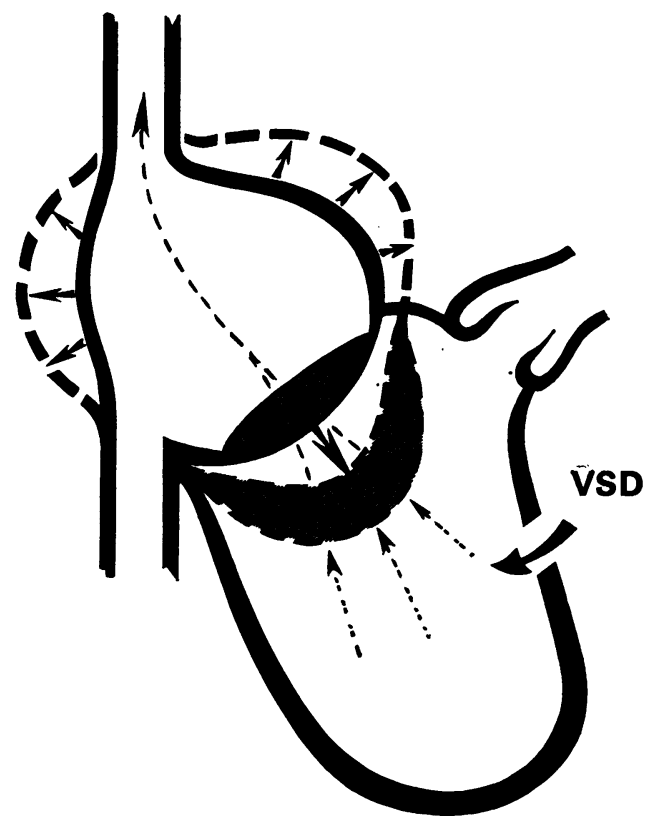

FIG. I9 Mechanism of tricuspid dysfunction. Shunting blood flow opposes the normal descent of the closed tricuspid floor during systole, and makes the septal leaflet of the valve vibrate. Such an hypothesis accounts for the decreased $s$ wave and the characteristic indentations of its descending limb (see text).

the ascending limb of the $s$ wave (Kalmanson et al., I972d). These combined effects explain the balanced occurrence of indentations on its ascending limb during inspiration, particularly pronounced when an organic orificial pulmonary stenosis already exists, as in Group 4.

\section{Correlations with phasic flow velocity pattern} of shunt

A) Analysis of flow velocity pattern of shunt Although a more detailed study is in preparation, the main results can be summarized as follows.

Apart from a minute right-to-left shunt in very early systole in some patients, the shunt occurs from left to right throughout systole, either overlapping early diastole, or continuing throughout diastole. Whichever pattern is present, the shunt is maximum during mid- and end-systole, and may have secondary maxima during early diastole and/or atrial contraction.

These findings may be surprising at first sight, on account of the well-known pansystolic (and only systolic) phonocardiographic timing of the ventricular septal defect murmur (Feruglio and Gun- ton, 1960; Hollman et al., 1963; Deuchar, 1964; Fenig et al., 1965; Luisada, 1965; Fishleder, 1966). It is noteworthy that associated diastolic murmurs have been ascribed to associated pulmonary or aortic regurgitation to persistent ductus arteriosus or to increased mitral flow, but save for Wood, Magidson, and Wilson (1954), never to a prolongation of the shunt during diastole.

Our findings, however, are in general agreement with those of Gamble and co-workers (1965), as well as with those of Mesel (1967).

Gamble, using a fibre-optics cardiac catheter, recorded an increase in oxygen saturation in the right ventricle mainly during systole, but also in early diastole, as well as during atrial contraction, depending on the pulmonary/systemic flow ratio and size of the defect. Mesel, using an electromagnetic cuff flowmeter probe surgically implanted around a hole made in the interventricular septum of dogs also noted that a substantial part (one-third to one-fourth) of the total shunt flow occurred during early and mid-diastole.

B) Jugular venous versus ventricular septal defect shunt flow velocity patterns a) During systole: the main anomalies of the jugular venous flow curves (indentations and decreased amplitude of the descending limb of the $s$ wave) occur during mid and end-systole, i.e. at the period of maximum amplitude of velocity of the shunt. This timing supports the proposed hypothesis of a functional disturbance in behaviour of the tricuspid valve.

b) During diastole: no clear-cut correlation can be displayed since the jugular venous flow curve is, in most instances, normal. However, it should be pointed out that the diastolic shunt flow velocity waves are either of very short duration (Fig. I6) or of small amplitude, and therefore negligible with respect to the systolic shunting flow velocity.

These remarks may well account for the discrepancies found in diastole between the two flow patterns. Only massive diastolic regurgitation (as in pulmonary incompetence or ruptured aneurysm of Valsalva) is capable of inducing a diastolic disturbance in the jugular venous flow tracing (Kalmanson et al., 1972d).

Correlations with right ventricular pressure and volume of shunt flow

Analysis of the results showed no linear correlation between anomalies of the jugular flow velocity pattern and quantitative values of right ventricular pressure or of shunt flow volume. 
However, a satisfactory correspondence could be elicited between specific patterns and the type of ventricular septal defect as shown in Table $I$.

Group I Typical pattern of ventricular septal defect during expiration with a normal pattern during inspiration occurred only with normal or almost normal pressures.

Group $2 A$ A normal or only slightly decreased amplitude of the $s$ wave throughout the respiratory cycle $(20 \mathrm{~cm} / \mathrm{sec}$ peak velocity or more) was found in all cases with moderate to large shunt flow and with right ventricular pressure less than 70 per cent of aortic pressure (Fig. 5).

Group $2 B$ An overall decreased amplitude of the $s$ wave was the common pattern of patients with large shunt flow and right ventricular pressure more than 70 per cent of aortic pressure. In 6 of 7 of these patients a conspicuously deep a wave was also elicited (Fig. I0).

Group 4 Characteristic pattern of ventricular septal defect plus occurrence of pronounced indentations or delay - of the ascending limb of the $f$ wave during inspiration is probably indicative of the patients having a ventricular septal defect associated with pulmonary stenosis, or of having Fallot's tetralogy. Generally, early occurrence of the typical indentations of the $s$ wave is highly suggestive of a large shunt, and the appearance of a deep a wave with a general decrease of amplitude of the s wave is highly suggestive of a major rise in right ventricular pressure (group 3, Fig. Io).

Thus, careful analysis of the anomalies of the curve enables clinical grading of shunt volume and of right ventricular pressure to be determined, as well as establishing the diagnosis of an associated pulmonary stenosis.

\section{Jugular venous flow velocity versus pulse tracings}

The striking difference in sensitivity between these two types of curve may be surprising at first. However, it should be borne in mind that the jugular venous pulse tracing reflects the absolute value of the instantaneous pressure within the internal jugular vein, which is usually not affected by tricuspid dysfunction, especially when the shunt is small or when right ventricular pressure is normal, whereas jugular venous blood flow is a much more sensitive measure of haemodynamic disturbances because it is determined by the pressure gradient (McDonald, 1960; Kalmanson et al., 1972c). This pressure gradient is most likely to be altered by tricuspid dysfunction, though on too small a scale to be recorded by the usual pressor sensors.

\section{Differential diagnosis}

Apart from the sensitivity, the reliability of the described patterns seems satisfactory though some diseases may simulate ventricular septal defect at first sight. This is mainly the case in 4 diseases which interfere with venous return: atrial septal defect, tricuspid insufficiency, and pulmonary stenosis and/or right ventricular or pulmonary arterial hypertension.

a) Atrial septal defect We have described how the $\mathrm{s}$ wave is prematurely cut off, but the descending limb falls precipitously beyond the zero line, and never presents the typical indentations shown in ventricular septal defect. In only one of these cases of septal defect could the confusion have arisen. This patient had perforation of the interventricular septum caused by myocardial infarction with secondary pulmonary hypertension, a situation where the differential diagnosis from atrial septal defect is not likely to be raised. A difficulty still exists when ventricular septal defect is associated with atrial septal defect, or when the ventricular septal defect shunts partly through the interspace between the septal and anterior leaflets of the tricuspid valve. This is undoubtedly a limitation of the method.

b) Tricuspid incompetence The confusion is not likely to arise whenever the tricuspid regurgitation is large, because the systolic wave of the jugular venous flow velocity curve then is entirely negative, an eventuality that never occurs in ventricular septal defect.

However, in small degrees of tricuspid incompetence, the $s$ wave may be simply prematurely cut off, and present an early steep descending limb, as in some cases of ventricular septal defect. Even then the difficulty may be solved by recording changes with respiration: inspiration enhances the anomalies caused by tricuspid incompetence whereas it decreases those caused by ventricular septal defect.

c) Pulmonary stenosis Typically, in pulmonary stenosis, it is the ascending limb that shows the saw-tooth indentations, and not the descending limb as in ventricular septal defect. However, in ventricular septal defect both limbs can show the diagnostic notches, but then those on the ascending limb only occur during inspiration. When both lesions are associated, as in Fallot's tetralogy, it may demand careful examination of the curve to ascertain the right diagnosis. Then the anomalies of the curve must be compared to the other clinical or haemodynamic data.

d) Pulmonary hypertension with a closed septum A delayed peak of the $s$ wave is usually present, no indentations can be found, a negative wave in early diastole may occur. 
e) Two rare diseases may be difficult to differentiate from ventricular septal defect when associated with aortic incompetence; first, a Valsalva aneurysm ruptured into the right ventricle: in one case the diagnosis was established by the anomalies of the diastolic wave, because the shunt is continuous systolic and diastolic and therefore impedes the normal function of the tricuspid valve during both systole and diastole. In a similar way, an anomalous fistula between coronary artery and right ventricle can be assumed to lead to the same diagnostic difficulties. Nevertheless, these difficulties in differential diagnosis, though possible, should not be exaggerated, and in current practice the use of the jugular venous flow velocity curve appears to be quite effective in the diagnosis of ventricular septal defect.

\section{Conclusions}

The recording of the pattern of the jugular venous flow velocity turns out to be a reliable method of assessing in an easy, quick, and non-injurious way the diagnosis of congenital ventricular septal defect.

Moreover, it can distinguish in many instances the case with or without a large shunt, and with or without pulmonary arterial hypertension.

During acute myocardial infarction, when a loud pansystolic murmur develops, this method can help to discriminate between perforation of the interventricular septum, mitral incompetence caused by ruptured chordae tendineae or papillary muscle infarction, and functional tricuspid incompetence caused by sudden congestive cardiac failure. In situations where cardiac catheterization is not always feasible, and may even be dangerous, the practical value of the non-invasive Doppler method deserves to be emphasized.

The data provided by the intracardiac velocity measurements at the site of the defect with an ultrasonic Doppler catheter-tip velocimeter seem to support the pathophysiological explanation of the basic anomalies of the jugular venous flow velocity tracing, which depends on a systolic malfunction of the tricuspid valve and ring, provoked by the shunting flow.

The authors are grateful to Dr. J. N. Mercier (Paris) for referring patients and Dr. D. Tunstall-Pedoe (Oxford) for his suggestions and correction of the English translation.

\section{References}

Bory, M. (1966). Le fugulogramme - Son Intérêt en Cardiologie, p. IO2. Meiffren, Marseille.

Brecher, G. A. (1956). Venous Return, Chapter IX. Grune and Stratton, New York.
Chiche, P., Kalmanson, D., Veyrat, C., and Toutain, G. (I968) Enregistrement transcutané du flux artériel par fluxmètre directionnel à effet Doppler. Description d'un appareillage et premiers résultats. Bulletin et Mémoires de la Société Médicale des Hôpitaux de Paris, 119, 87.

Colman, A. L. (1966). Clinical Examination of the fugular Venous Pulse, p. 72. Charles C. Thomas, Springfield, Illinois.

Corone, P., Guérin, F., Gaudeau, S., Doyon, F., and Ruet, J. C. (1972). Etude du pronostic spontané des communications interventriculaires. Coeur, 3, 237.

Deuchar, D. C. (1964). Clinical Phonocardiography, p. 108. The English Universities Press, London.

Fenig, S., Hilsenrath, J., Steinfeld, L., Lasser, J., Genkins, G., and Gordon, A. J. (1965). Correlation of the murmur of interventricular septal defect with pressure differences between the ventricles. British Heart fournal, $27,193$.

Feruglio, G. A., and Gunton, R. W. (1960). Intracardiac phonocardiography in ventricular septal defect. Circulation, $21,49$.

Fishleder, B. (1966). Exploration Cardiovascular y Fonomecanocardiografia Clinica. Prensa Médica Mexicana, p. 321. Mexico.

Gamble, W., Hugenholtz, P. G., Monroe, R. G., Polanyi, M., and Nadas, A. S. (1965). The use of fiberoptics in clinical cardiac catheterization. Intra-cardiac oxymetry. Circulation, 31, 328.

Gamboa, R., Gersony, W. M., Hugenholtz, P. G., and Nadas, A. S. (1965). External measurement of the isovolumic relaxation phase as an indicator of pulmonary artery pressure in ventricular septal defects. American fournal of Cardiology, 16, 665 .

Gelfand, D. (1965). Tracings of the venous system and from thoracic organs. Examination of the Cardiac Patient, Chapter Io. Ed. by A. A. Luisada. McGraw-Hill, New York.

Hartman, H. (1960). The jugular venous tracing. American Heart fournal, 59, 698.

Hollman, A., Morgan, J. J., Goodwin, J. F., and Fields, H. (1963). Auscultatory and phonocardiographic findings in ventricular septal defect. A study of 93 surgically treated patients. Circulation, 28, 94 .

Kalmanson, D., Toutain, G., Novikoff, N., and Derai, C. (I972a). Retrograde catheterization of left heart cavities in dogs by means of an orientable directional Doppler catheter-tip flow-meter: a preliminary report. Cardiovascular Research, 6, 309.

Kalmanson, D., Veyrat, C., and Chiche, P. (1968). Le retour veineux droit enregistré par voie transcutanée au niveau de la veine jugulaire interne chez le sujet normal. Interprétation physiologique des courbes. Bulletin et Mémoires de la Société Médicale des Hôpitaux de Paris, II9, 873.

Kalmanson, D., Veyrat, C., and Chiche, P. (197I). Atrial versus ventricular contribution in determining systolic venous return. A new approach to an old riddle. Cardiovascular Research, 5, 293.

Kalmanson, D., Veyrat, C., Derai, C., and Chiche, P. (1972b). Diagnostic value of jugular venous flow velocity trace in right heart diseases. In Blood Flow Measurement, p. 57. Ed. by C. Roberts. Sector Publishing, London.

Kalmanson, D., Veyrat, C., Derai, C., Savier, C. H., Berkman, M., and Chiche, P. (1972c). Non-invasive technique for diagnosing atrial septal defect and assessing shunt volume using directional Doppler ultrasound. Correlations with phasic flow velocity patterns of the shunt. British Heart fournal, 34, 981.

Kalmanson, D., Veyrat, C., Witchitz, S., Derai, C., and Chiche, P. (1972d). Les dysfonctionnements tricuspidiens: une nouvelle entité physiopathologique. Annales de Cardiologie et d'Angéiologie, 21, 433. 
Luisada, A. A. (1965). From Auscultation to Phonocardiography, p. 285. C. V. Mosby, St-Louis.

McDonald, D. A. (1960). Bloodflow in Arteries. Edward Arnold, London.

Mesel, E. (1967). Instantaneous blood flow through ventricular septal defects (abstract). Circulation, 36, Suppl. 2, I86.

Nadas, A. S., and Fyler, D. (1968). Ventricular septal defect; review of current thoughts. Archives of Disease in Childhood, 43, 268.
Wood, P. (1950). Diseases of the Heart and Circulation, p. 216. Eyre and Spottiswoode, London.

Wood, P., Magidson, O., and Wilson, P. A. O. (1954). Ventricular septal defect with a note on acyanotic Fallot's tetralogy. British Heart fournal, 16, 387.

Requests for reprints to Dr. D. Kalmanson, Fondation Ophtalmologique A. de Rothchild, 29 rue Manin, 75019 Paris, France. 